\title{
Prediksi Laju Sedimentasi di Perairan Teluk Benoa Menggunakan Pemodelan Numerik
}

\author{
I Putu Ranu Fajar Maharta a*, I Gede Hendrawan a, Yulianto Suteja a \\ a Program Studi Ilmu Kelautan, Fakultas Kelautan dan Perikanan, Universitas Udayana, Kampus UNUD Bukit Jimbaran, Bali 80361, Indonesia \\ * Penulis koresponden. Tel.: +62-857-3743-9907 \\ Alamat e-mail: ranufajar123@gmail.com
}

Diterima (received) 22 November 2017; disetujui (accepted) 18 Februari 2018; tersedia secara online (available online) 21 Februari 2018

\begin{abstract}
Benoa Bay is one of the unique ecosystems on the island of Bali because it is a shallow estuary area and has an ecosystem that is important for the waters of the mangrove ecosystem and seagrass. In recent years, Benoa Bay has been reported to have undergone siltation due to sedimentation. However, there has not been much scientific study of the sedimentation rate occurring in Benoa Bay. The study of sedimentation will provide an overview of the rate of sedimetation in the study area. Numerical modeling is one of the most commonly used methods to describe hydrodynamic processes in waters, which are the main drivers of the process of movement of pollutants in waters such as waste, sediment, and others. Thus, the study of sedimentation rate, either spatially or temporally, needs to be done in the waters of Benoa Bay using numerical modeling. The results of this study show that sedimentation rates in Benoa Bay have a minimum value of $1.08 \times 10^{-6}$ and a maximum of $24.88 \mathrm{~kg} / \mathrm{m}^{2} /$ day with an average of $0.57 \mathrm{~kg} / \mathrm{m}^{2} / \mathrm{day}$. High sedimentation rates occur in the western part of the bay, on the river route, and in the northern part of the bay, between Serangan Island and Mertasari beach. Areas that potentially experience silting in Benoa Bay include the southern port of Benoa Harbor which reaches $0.23 \mathrm{~m} / \mathrm{year}$, the waters north of Serangan Island reaching $0.008 \mathrm{~m} / \mathrm{year}$, and the area close to the estuary which reaches $0.35 \mathrm{~m} /$ year.
\end{abstract}

Keywords: Benoa Bay; sedimentation rate; silting; FVCOM

\begin{abstract}
Abstrak
Teluk Benoa adalah salah satu kawasan ekosistem yang unik di Pulau Bali karena merupakan kawasan estuari dangkal dan memiliki ekosistem yang penting bagi perairan yaitu ekosistem mangrove dan padang lamun. Beberapa tahun belakangan ini, Teluk Benoa dilaporkan telah mengalami pendangkalan akibat sedimentasi. Namun demikian masih belum banyak ditemukan kajian secara ilmiah terhadap laju sedimentasi yang terjadi di Teluk Benoa. Studi mengenai sedimentasi akan memberikan Gambaran terkait dengan laju sedimetasi pada daerah penelitian. Pemodelan numerik adalah salah satu metode yang sering digunakan untuk mengGambarkan proses hidrodinamika di perairan yang merupakan penggerak utama dari proses pergerakan polutan di perairan seperti limbah, sedimen, dan lainnya. Dengan demikian studi terhadap laju sedimentasi, baik secara spasial maupun temporal perlu dilakukan di perairan Teluk Benoa menggunakan pemodelan numerik. Hasil studi ini menunjukkan bahwa laju sedimentasi di Teluk Benoa memiliki nilai minimum $1.08 \times 10^{-6}$ dan maksimum $24.88 \mathrm{~kg} / \mathrm{m}^{2} / \mathrm{hari}$ dengan rata-rata $0.57 \mathrm{~kg} / \mathrm{m}^{2} / \mathrm{hari}$. Dimana laju sedimentasi yang tinggi terjadi di bagian barat teluk pada jalur sungai dan di bagian utara teluk, di antara Pulau Serangan dan pantai Mertasari. Daerah yang berpotensi mengalami pendangkalan di Teluk Benoa meliputi daerah Selatan Pelabuhan Benoa yang mencapai $0.23 \mathrm{~m} / \mathrm{tahun}$, perairan di Utara Pulau Serangan yang mencapai $0.008 \mathrm{~m} /$ tahun, dan daerah yang dekat dengan muara sungai yang mencapai $0.35 \mathrm{~m} /$ tahun.
\end{abstract}

Kata Kunci: Teluk Benoa; laju sedimentasi; pendangkalan; FVCOM 


\section{Pendahuluan}

Teluk Benoa adalah salah satu kawasan ekosistem yang unik di Pulau Bali karena merupakan kawasan estuari dangkal dan memiliki ekosistem yang penting bagi perairan yaitu ekosistem mangrove dan padang lamun. Karena keunikan tersebut, di Teluk Benoa terdapat banyak aktivitas manusia seperti wisata bahari, budidaya perikanan, jalan tol, tempat pembuangan akhir (TPA) Suwung, serta Pelabuhan Benoa yang memiliki aktivitas kapal yang sangat padat.

Perairan Teluk Benoa dilaporkan telah mengalami pendangkalan (tribunnews, 2016), hal ini terlihat juga dengan aktifitas pengerukan jalur pelayaran yang dilakukan oleh PT Pelindo. Pendangkalan estuari dapat terjadi dimana-mana akibat dari proses transport material, baik terbawa oleh sungai maupun run off secara langsung dari daerah daratan (Qiao et al., 2009; Kessel et al., 2011; Chizom Dike and Agumwamba, 2013; Solihudin et al., 2014; Weilbeer, 2014; Roswaty et al., 2014; Ge et al., 2015; Guerreiro et al., 2015; Noya et al., 2017; Kim et al., 2017). Laju sedimentasi yang tidak terkontrol akan berakibat pada proses pendangkalan yang semakin cepat sehingga dapat mengakibatkan rusaknya ekosistem dan berdampak pada sulitnya nelayan untuk mendapatkan hasil tangkapan. Menurut penelitian yang dilakukan oleh Risuana et al. (2017) menunjukkan konsentrasi sedimen tersuspensi pada permukaan Perairan Teluk Benoa berkisar antara $94 \mathrm{mg} / \mathrm{l}$ sampai $682.89 \mathrm{mg} / \mathrm{l}$ dimana konsentrasi sedimen tersuspensi yang tertinggi terdapat pada musim kemarau dan saat kondisi pasang menuju surut. Sedangkan menurut Hendrawan et al. (2016), menujukkan konsentrasi sedimen tersuspensi yang tinggi pada dasar Perairan Teluk Benoa yaitu di daerah lalu lintas kapal yang mencapai $1270 \mathrm{mg} / \mathrm{l}$. Hasil ini menunjukkan adanya potensi terjadi sedimentasi yang tinggi di Perairan Teluk Benoa.

Pemodelan numerik adalah salah satu metode yang sering digunakan untuk mengGambarkan proses hidrodinamika di perairan yang merupakan penggerak utama dari proses pergerakan polutan di perairan seperti limbah, sedimen, dan lainnya. Penelitian menggunakan pemodelan numerik di Perairan Teluk Benoa banyak dilakukan seperti pemodelan pola arus (Ningsih and Azhar, 2013; Hendrawan and Asai, 2014), dan pemodelan penyebaran polutan (Hendrawan dan Asai, 2008; Hendrawan dan
Ardana, 2010; Ardana and Mahendra, 2012; Rachman et al., 2016). Studi tentang transpor sedimen pernah dilakukan sebelumnya oleh Hendrawan and Asai (2008) menggunakan kombinasi antara penginderaan jauh dan metode Princeton Ocean Model (POM). Penelitian Rachman et al (2016) menggunakan metode FVCOM dengan hasil pada dasar perairan memiliki konsntrasi sedimen tersuspensi yang tinggi pada daerah mulut teluk sampai area pelabuhan, akan tetapi penelitian ini memiliki kekurangan pada kondisi awal yang dianggap nol dan validasi data yang dilakukan tidak mempertimbangkan semua jenis sedimen. Beberapa penelitian sebelumnya hanya melakukan simulasi mengenai transpor sedimen, namun belum pernah dilakukan simulasi mengenai laju sedimentasi yang terjadi di Teluk Benoa. Pemodelan transpor sedimen menggunakan FVCOM dapat digunakan untuk mengetahui laju sedimentasi, sehingga didapatkan hasil yang lebih mendekati kondisi sebenarnya dilapangan.

Dengan adanya indikasi mengenai sedimentasi di Perairan Teluk Benoa, maka akan timbul potensi terjadi pendangkalan yang dapat mengganggu ekosistem serta alur pelayaran di Teluk Benoa. Berdasarkan permasalahan tersebut pada penelitian ini dilakukan kajian mengenai laju sedimentasi secara spasial untuk mengetahui daerah yang berpotensi mengalami pendangkalan.

\section{Metode Penelitian}

\subsection{Lokasi penelitian}

Penelitian ini dilakukan di Perairan Teluk Benoa dan sungai yang bermuara di Teluk Benoa. Waktu pengambilan data insitu dilakukan pada tanggal 12 Desember 2016. Simulasi model dilakukan mulai dari tanggal 10 Desember 2016 sampai 25 Januari 2017 pada saat musim hujan agar dapat diketahui variasi laju sedimentasi pada musim hujan pada saat masukan sedimen tertinggi dari sungai (Risuana et al., 2017). Penelitian ini menggunakan 14 titik pengambilan sampel data insitu pada Perairan Teluk Benoa dan 4 titik pengambilan sampel pada setiap sungai yang bermuara di Perairan Teluk Benoa. Lokasi pengambilan sampel dapat di lihat pada Gambar 1.

\subsection{Model hidrodinamika}

Finite Volume Coastal Ocean Model (FVCOM) merupakan model perairan laut 3 dimensi dengan 
sistem grid yang tidak terstruktur (unstructured triangular grid) sehingga dapat memberikan hasil yang lebih baik untuk kondisi garis pantai yang sangat kompleks (Chen et al., 2010).

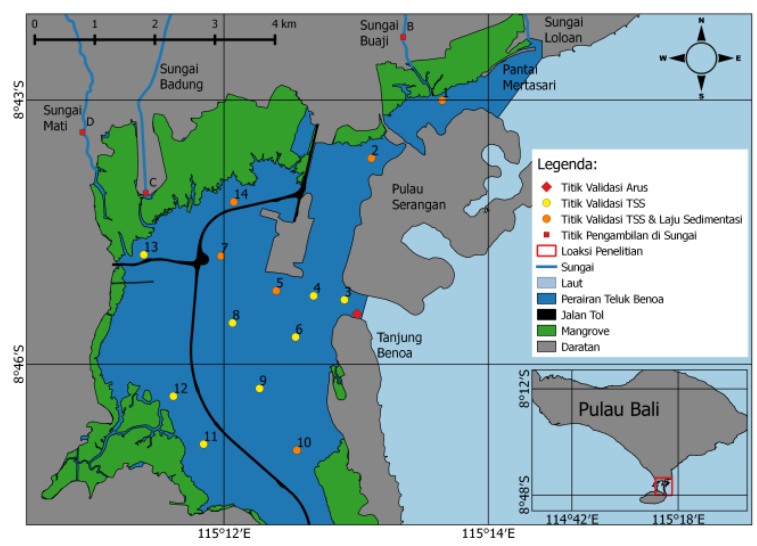

Gambar 1. Peta lokasi pengambilan data insitu di Perairan Teluk Benoa

Persamaan hidrodinamika yang terdapat dalam model FVCOM terdiri dari persamaan momentum (persamaan 1-3), kontinuitas (persamaan 4), suhu (persamaan 5), salinitas (persamaan 6), dan densitas (persamaan 7) (Chen et al., 2010):

$$
\begin{aligned}
& \frac{\partial u}{\partial t}+u \frac{\partial u}{\partial x}+v \frac{\partial u}{\partial y}+w \frac{\partial u}{\partial z}-f v=-\frac{1}{\rho} \frac{\partial P}{\partial x}+\frac{\partial}{\partial z}\left(K_{m} \frac{\partial u}{\partial z}\right)+F_{u} \\
& \frac{\partial v}{\partial t}+u \frac{\partial v}{\partial x}+v \frac{\partial v}{\partial y}+w \frac{\partial v}{\partial z}-f u=-\frac{1}{\rho} \frac{\partial P}{\partial x}+\frac{\partial}{\partial z}\left(K_{m} \frac{\partial u}{\partial z}\right)+F_{v} \\
& \frac{\partial v}{\partial t}=-\rho g
\end{aligned}
$$$$
\frac{\partial u}{\partial x}+\frac{\partial v}{\partial y}+\frac{\partial w}{\partial z}=0
$$$$
\frac{\partial T}{\partial t}+u \frac{\partial T}{\partial x}+v \frac{\partial T}{\partial y}+w \frac{\partial T}{\partial z}=\frac{\partial}{\partial z}\left(K_{h} \frac{\partial T}{\partial z}\right)+F_{t}
$$$$
\frac{\partial s}{\partial t}+u \frac{\partial s}{\partial x}+v \frac{\partial s}{\partial y}+w \frac{\partial s}{\partial z}=\frac{\partial}{\partial z}\left(K_{h} \frac{\partial S}{\partial z}\right)+F_{s}
$$

$$
\rho=\rho(T, S)
$$

dimana $x, y$, dan $z$ adalah arah timur-barat, utaraselatan, dan juga vertikal dalam sistem koordinat kartesian; $u, v$, dan $w$ adalah komponen kecepatan arus $(\mathrm{m} / \mathrm{s})$ untuk arah $x, y, z ; T$ adalah temperatur $\left({ }^{\circ} \mathrm{C}\right) ; S$ adalah salinitas (psu); $Q$ adalah denistas $\left(\mathrm{kg} / \mathrm{m}^{3}\right) ; P$ adalah tekanan $(\mathrm{Pa}) ; f$ adalah gaya coriolis $\left({ }^{\circ}\right) ; g$ adalah gravitasi $(\mathrm{m} / \mathrm{s}) ; K_{m}$ adalah koefisien eddy viscosity secaa vertikal $\left(\mathrm{m}^{2} / \mathrm{s}\right)$; dan $K_{h}$ adalah koefisien thermal eddy diffusion secara vertikal $\left(\mathrm{m}^{2} / \mathrm{s}\right) . F_{u}, F_{v}, F_{t}$, dan $F_{s}$ secara berturutturut merepresentasikan gesekan arah $\mathrm{x}$ dan $\mathrm{y}$, thermal, dan difusi salinitas $(\mathrm{N})$.

Pada desain model, keberadaan mangrove diabaikan sehingga untuk daerah yang semula merupakan kawasan mangrove akan dihilangkan dan dianggap sebagai wilayah perairan. Hal tersebut dilakukan karena pada saat pasang kawasan mangrove juga akan terendam air laut sehingga pada bagian dalam mangrove juga masih terdapat arus meskipun dengan kecepatan sangat

\begin{tabular}{|c|c|c|}
\hline \multicolumn{2}{|l|}{ Item } & Keterangan \\
\hline \multicolumn{2}{|l|}{ Grid } & $\begin{array}{l}\text { Grid tak-terstruktur dengan } \\
\text { resolusi } 50-500 \mathrm{~m} \text { (resolusi } \\
\text { yang dimaksud merupakan } \\
\text { jarak antara } 2 \text { node terdekat) } \\
\text { seperti Gambar } 2\end{array}$ \\
\hline \multicolumn{2}{|l|}{ Layer } & $\begin{array}{l}\text { Uniform layer dengan } 10 \text { sigma } \\
\text { Layer }\end{array}$ \\
\hline \multicolumn{2}{|c|}{$\begin{array}{l}\text { Batas terbuka } \\
\text { boundary) }\end{array}$} & $\begin{array}{l}\text { Elevasi pasang surut (S2, M2, } \\
\text { K1 dan O1), suhu dan salinitas }\end{array}$ \\
\hline \multirow{2}{*}{$\begin{array}{l}\text { Model } \\
\text { forcing }\end{array}$} & Debit sungai & Model forcing \\
\hline & $\begin{array}{l}\text { Kondisi } \\
\text { meteorologi }\end{array}$ & \\
\hline \multicolumn{2}{|c|}{ Waktu simulasi } & 47 hari \\
\hline \multicolumn{2}{|c|}{ Langkah waktu (time step) } & 1 detik \\
\hline
\end{tabular}
kecil.

Tabel 1

Desain model hidrodinamika

\subsection{Model transpor sedimen}

Pada model transpor sedimen yang terdapat dalam FVCOM mencakup model untuk transpor bed load dan suspended load. Dalam implementasi dari model tersebut konsentrasi dari setiap jenis sedimen dihitung secara terpisah dan kemudian ditambahkan untuk menghasilkan total konsentasi sedimen. Model untuk menghitung nilai suspended load adalah pendekatan berbasis konsentrasi dengan persamaan 8 .

$$
\begin{aligned}
& \frac{\partial C i}{\partial t}+\frac{\partial u \cdot C i}{\partial x}+\frac{\partial u \cdot C i}{\partial y}+\frac{\partial(w-w i) C i}{\partial z}=\frac{\partial}{\partial x}\left(A_{h} \frac{\partial C i}{\partial x}\right)+ \\
& \frac{\partial}{\partial x}\left(A_{h} \frac{\partial C i}{\partial y}\right)+\frac{\partial}{\partial z}\left(K_{h} \frac{\partial C i}{\partial z}\right)
\end{aligned}
$$


dimana $C_{i}$ adalah nilai konsentrasi dari sedimen $\left(\mathrm{kg} / \mathrm{m}^{3}\right)$ yang tersuspensi, $A_{h}$ adalah nilai viskositas eddy secara horizontal $\left(\mathrm{m}^{2} / \mathrm{s}\right)$, dan $K_{h}$ adalah viskositas eddy secara vertikal $\left(\mathrm{m}^{2} / \mathrm{s}\right)$. Sedangkan untuk $w_{i}$ adalah nilai dari settling velocity (kecepatan mengendap) $(\mathrm{m} / \mathrm{s})$ yang disesuaikan dengan masukan jenis sedimen yang dimasukkan ke dalam model. Pada area permukaan, nilai flux boundary condition yang digunakan untuk konsentrasi sedimen adalah sebagai berikut :

$$
K h \frac{\partial C i}{\partial z}=0, z=\zeta
$$

dimana $\zeta$ adalah representasi sigma koordinat untuk arah vertikal $(z)$. Untuk area dasar, nilai sediment flux memiliki perbedaan antara deposisi dan erosi. Untuk nilai deposisi sedimen $\left(D_{i}\right)$ $\left(\mathrm{kg} / \mathrm{m}^{3}\right)$ digunakan persamaan sebagai berikut :

$K h \frac{\partial C i}{\partial z}=E i-D i, z=\zeta$

dan untuk erotion rate $\left(E_{i}\right)\left(\mathrm{kg} / \mathrm{m}^{3}\right)$ dapat dihitung dengan persamaan sebagai berikut :

$$
E i=\Delta t Q i(1-P b) F b i\left(\frac{\tau b}{\tau C i}-1\right)
$$

dimana $Q_{i}$ adalah fluks erosi, $P_{b}$ adalah porositas yang terdapat di dasar perairan $(\%), F_{b i}$ adalah friction dari sedimen di dasar $(\mathrm{m}), \tau_{b}$ adalah tekanan bottom shear stress $\left(\mathrm{N} / \mathrm{m}^{2}\right)$, dan $\tau_{c i}$ adalah nilai dari critical shear stress $\left(\mathrm{N} / \mathrm{m}^{2}\right)$ dari sediment tersebut.

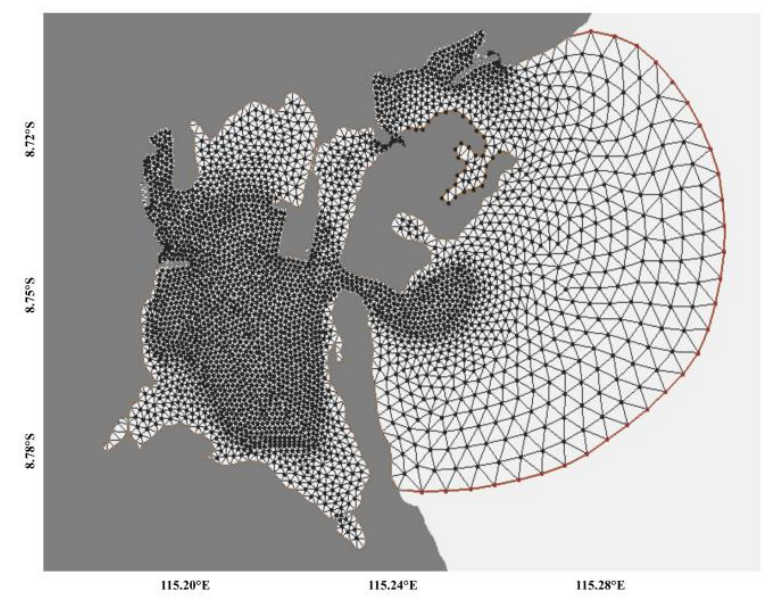

Gambar 2. Desain grid model

Dalam proses untuk melakukan simulasi model diperlukan beberapa masukan yang harus diberikan. Masukan ini merupakan pengaturan dari model tersebut yang dikondisikan dengan kondisi lapangan ataupun standar nilai yang telah ada sebelumnya, sedangkan pengaturan untuk jenis sedimen yang digunakan akan disesuaikan dengan jenis sedimen yang diperoleh dari lapangan. Parameter yang terdapat dalam masukan tersebut dapat dilihat dalam Tabel 2.

Tabel 2

\begin{tabular}{|c|c|c|}
\hline Parameter & Nilai & Sumber \\
\hline $\mathrm{K}_{\mathrm{h}}\left(\mathrm{m}^{2} / \mathrm{s}\right)$ & $10^{-5}$ & $\begin{array}{l}\text { Chen et al., } \\
2010\end{array}$ \\
\hline $\operatorname{Ah}\left(\mathrm{m}^{2} / \mathrm{s}\right)$ & $2 \times 10^{-1}$ & $\begin{array}{l}\text { Chen et al., } \\
2010\end{array}$ \\
\hline $\begin{array}{l}\text { Bottom shear stress } \\
\left(\mathrm{N} / \mathrm{m}^{2}\right)\end{array}$ & 0.047 & $\begin{array}{l}\text { Zhang et al., } \\
2014\end{array}$ \\
\hline Bed thickness (m) & 3 & $\begin{array}{l}\text { Chen et al., } \\
2006\end{array}$ \\
\hline Bed porosity $(\%)$ & 40 & $\begin{array}{l}\text { Chen et al., } \\
2010\end{array}$ \\
\hline Bottom friction $(\mathrm{m})$ & 0.0024 (lumpur) & $\begin{array}{l}\text { Zhang et al., } \\
2014\end{array}$ \\
\hline
\end{tabular}

Desain model hidrodinamika

\subsection{Sumber Data dan Verifikasi Hasil Model}

Penelitian ini menggunakan data primer dan sekunder sebagai masukan serta untuk memvalidasi hasil simulasi model. Data primer yang digunakan pada penelitian ini berupa data insitu seperti suhu, salinitas, Total Suspended Solid (TSS), debit sungai, jenis serta berat sedimen, dan laju sedimentasi. Data sekunder yang digunakan berupa data batimetri hasil pengukuran tahun 2012 dan Dishidros TNI AL tahun 2006 seperti Gambar 3, data elevasi pasang surut di batas terbuka menggunakan elevasi yang dikembangkan oleh Ocean Research Institute (ORI), Universitas Tokyo (ORI-Tide) (Matsumoto et al.,1995).

\subsubsection{Pengukuran Debit Sungai}

Pengukuran debit sungai menggunakan metode yang dikembangkan oleh Shaw et al (2010) dengan menggunakan persamaan 12. Pada metode ini pengukuran debit sungai didasarkan pada persamaan dasar dalam menghitung debit $(Q)$ $\left(\mathrm{m}^{3} / \mathrm{s}\right)$ yakni perkalian antara kecepatan arus $(v)$ $(\mathrm{m} / \mathrm{s})$ dikalikan luas penampang $(a)\left(\mathrm{m}^{2}\right)$.

$Q=v \times a$ 

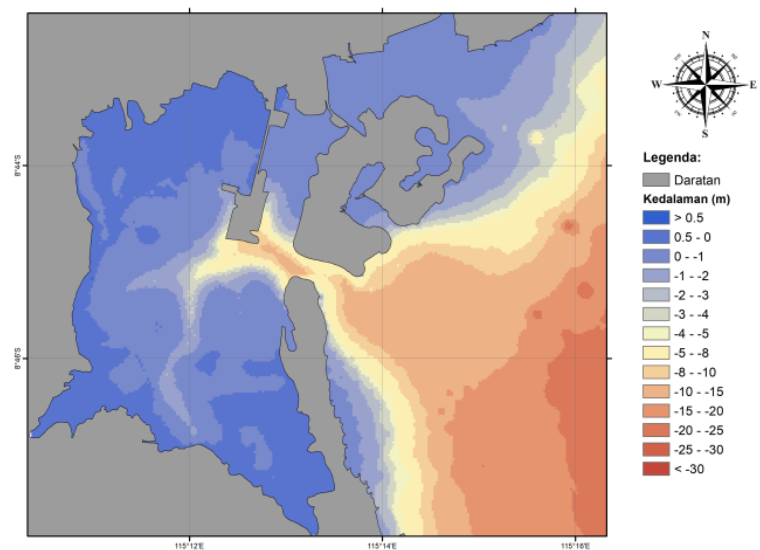

Gambar 3. Peta batimetri Teluk Benoa

Peningkatan akurasi dalam pengukuran debit sungai dilakukan dengan cara membagi lebar sungai menjadi beberapa bagian dengan panjang yang sama (Gambar 4). Pada setiap bagian tersebut diambil parameter berupa kecepatan arus $(v)(\mathrm{m} / \mathrm{s})$, kedalaman $(d)(\mathrm{m})$, dan lebar dari penampang sungai $(b)(\mathrm{m})$ yang diukur. Dari ketiga parameter tersebut kemudian didapatkan persamaan 13 (Shaw et al., 2010).

$Q=v \times \frac{\left(d_{i-1}+d_{i}\right)}{2} \times\left(b_{i}+b_{i-1}\right)$

dimana $Q$ adalah debit sungai $\left(\mathrm{m}^{3} / \mathrm{s}\right), v$ adalah kecepatan arus $(\mathrm{m} / \mathrm{s}), d$ adalah kedalaman perairan (m), dan $b$ adalah jarak (m).

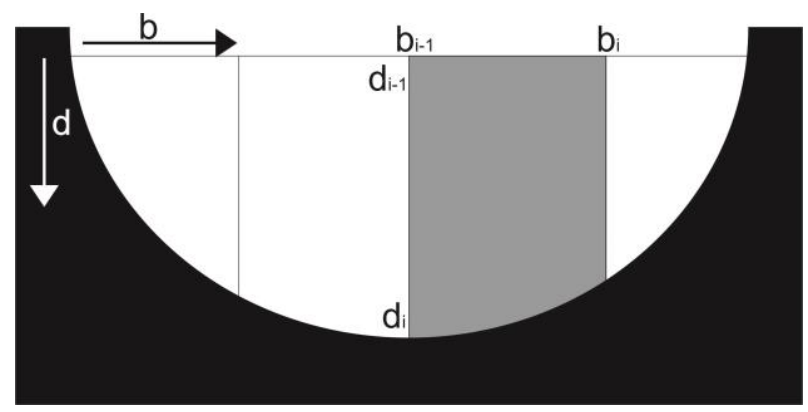

Gambar 4. Bagian-bagian penampang dalam pengukuran debit sungai (Shaw et al., 2010)

\subsubsection{Pengukuran konsentrasi dan jenis sedimen}

Pengukuran konsentrasi sedimen pada laut di ambil pada permukaan dan kolom perairan pada kedalaman 5 meter. Pengambilan sampel pada permukaan diambil pada titik 1 sampai 14, sedangkan pada kolom perairan diambil pada titik 3, 4 dan 5. Pengambilan sampel pada kolom perairan dilakukan untuk mengetahui variasi konsentrasi sedimen pada kolom perairan di jalur lalu lintas kapal pada area sekitar Pelabuhan Benoa sampai Mulut Teluk Benoa.
Pengukuran konsentrasi dan jenis sedimen juga dilakukan pada sungai yang bermuara di Teluk Benoa. Konsentrasi sedimen yang digunakan untuk masukan pada model menggunakan konsentrasi TSS pada air sungai. Pengambilan konsentrasi TSS pada sungai dilakukan pada waktu pengambilan yang sama seperti pengambilan data debit sungai. Jenis sedimen yang digunakan untuk masukan pada model merupakan ukuran diameter butir dari sedimen yang terbawa dari sungai menuju ke laut, dengan asumsi bahwa sedimen yang telah mengendap di dasar sungai memiliki ukuran butir yang sama dengan sedimen yang terbawa sampai ke laut. Pengambilan sedimen pada dasar sungai menggunakan alat ekman grap, kemudian di ambil sebanyak 50 gr untuk mengetahui diameter sedimen pada setiap sungai.

Metode yang digunakan dalam pengujian dan analisa sampel TSS mengikuti prosedur Standar Nasional Indonesia (SNI) No. 06-6989.3-2004 tentang cara uji padatan tersuspensi total (TSS) secara gravimetri. Sampel air yang dianalisis diaduk menggunakan pengaduk magnetik agar sampel air menjadi homogen. Sampel air yang telah homogen disaring menggunakan pompa vakum dengan kertas saring berukuran 2,5 $\mu \mathrm{m}$, kemudian kertas saring tersebut dikeringkan dengan menggunakan oven. Suhu yang digunakan untuk menghilangkan kadar air selama penyaringan yaitu dengan suhu $104^{\circ} \mathrm{C}$ selama 1 jam. Perhitungan TSS sesuai dengan SNI No. 066989.3-2004 dapat ditentukan dengan persamaan 14.

$T S S=\frac{A-B}{1 \text { liter }} \times 1000$

Dimana TSS adalah total suspended solid $\left(\mathrm{kg} / \mathrm{m}^{3}\right)$, A adalah berat kertas saring + residu kering $(\mathrm{kg})$, dan $\mathrm{B}$ adalah berat kertas saring $(\mathrm{kg})$.

\subsubsection{Sedimen trap}

Gambar 5 merupakan desain alat sediment trap yang digunakan pada penelitian ini. Sedimen yang terperangkap di dalam alat sediment trap kemudian disimpan ke dalam plastik sampel dan dikeringkan menggunakan oven dengan suhu $110^{\circ} \mathrm{C}$ selama 48 jam. Sampel sedimen yang telah kering dianalisis untuk diperoleh jenis sedimen, ukuran butir dari setiap jenis sedimen, dan berat dari masing-masing jenis sedimen. 
Alat sediment trap diletakkan selama 30 hari pada dasar Perairan Teluk Benoa. Peletakan alat sediment trap pada dasar perairan teluk bertujuan untuk menangkap sedimen yang terdeposisi pada dasar perairan teluk, sehingga data yang diperoleh berupa data laju sedimentasi yang berguna untuk memvalidasi hasil data laju sedimentasi pada model.

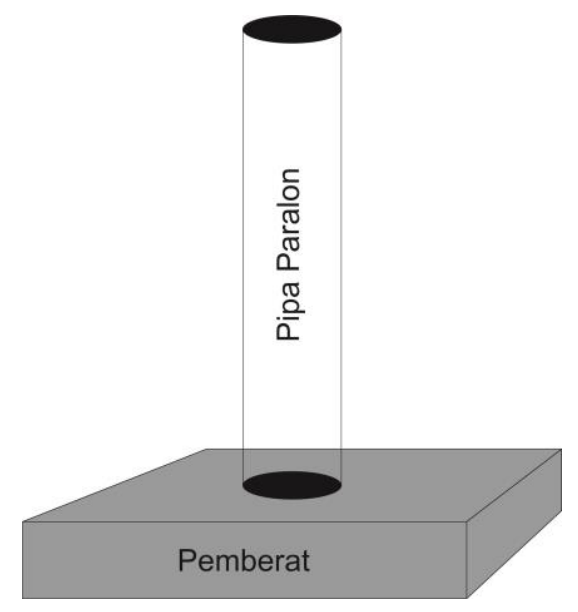

Gambar 5. Desain alat sediment trap

Perhitungan laju sedimentasi menggunakan persamaan 15 yang dikembangkan oleh Eaton et al. (1995).

$$
L S=\frac{\pi \times r \times r \times B S}{30 h a r i}
$$

dimana LS adalah laju sedimentasi $\left(\mathrm{kg} / \mathrm{m}^{2} / \mathrm{hari}\right), \pi$ $=22 / 7, \mathrm{r}$ adalah jari-jari dari sediment trap $(\mathrm{m})$, dan BS adalah berat sedimen $(\mathrm{kg})$.

\subsubsection{Verifikasi Hasil Model}

Data yang diperoleh dari simulasi model kemudian divalidasi dengan data primer maupun sekunder yang diperoleh di lapangan. Data elevasi pasang surut hasil model divalidasi dengan menggunakan data lapangan yang diukur di Tanjung Benoa selama 15 dari tanggal 14 Desember 2016 sampai 29 Desember 2016.

Data keceptan serta arah arus hasil model divalidasi dengan data hasil observasi lapangan yang diperoleh dari pengukuran langsung di lapangan dengan menggunakan alat ukur arus ADCP (Acoustic Doppler Current Profiler) pada tanggal 25 Juni 2015 sampai 11 Juli 2015 pada mulut Teluk Benoa dengan koordinat (115 $13^{\prime} 12,50 "$ BT dan $8^{\circ} 45^{\prime} 8,60^{\prime \prime}$ LS).
Validasi arus dilakukan dengan melakukan simulasi model hidrodinamika pada waktu yang bersamaan dengan waktu pengukuran data lapangan yaitu selama 19 hari dari tanggal 23 Juni - 11 Juli 2015.

Data konsentrasi TSS hasil model divalidasi dengan data primer yang diperoleh di lapangan. Data laju sedimentasi hasil model divalidasi dengan data laju sedimentasi yang diperoleh menggunakan alat sediment trap. Validasi data akan dilakukan menggunakan analisis korelasi dengan persamaan 16 dan RSME (Root Mean Square Error) dengan persamaan 17.

$$
\begin{aligned}
& r=\frac{\sum x y-\frac{\left(\sum x\right)\left(\sum y\right)}{n}}{\sqrt{\left(\sum x^{2}-\frac{\left(\sum x\right)^{2}}{n}\right)\left(\sum y^{2}-\frac{\left(\sum y\right)^{2}}{n}\right)}} \\
& R M S E=\sqrt{\frac{E_{i=1}^{i}(x-y)^{2}}{n}}
\end{aligned}
$$

dimana $x$ adalah nilai hasil pengamatan dilapangan dan y adalah nilai yang didapatkan dari hasil model, dan $\mathrm{n}$ adalah jumlah data.

\section{Hasil dan Pembahasan}

\subsection{Validasi hasil model}

\subsubsection{Validasi pasang surut}

Validasi dari hasil model perlu dilakukan dalam suatu pemodelaan numerik agar dapat diketahui sejauh mana penyimpangan dari hasil simulasi model yang telah dilakukan terhadap data lapangan. Berdasarkan Gambar 6 menunjukkan bahwa secara umum data elevasi hasil model dan data lapangan memiliki pola yang sama dengan korelasi yang tinggi yaitu 0,99. Perhitungan secara kuantitatif menggunakan RMSE menghasilkan perbedaan antara hasil model dan observasi lapangan sebesar $0,05 \mathrm{~m}$.

\subsubsection{Validasi arus}

Berdasarkan current rose seperti Gambar 7 menunjukkan pola pergerakan arus hasil pengukuran di lapangan dan simulasi model di Mulut Teluk Benoa memiliki pola yang serupa, dimana arus dominan bergerak ke arah timur 


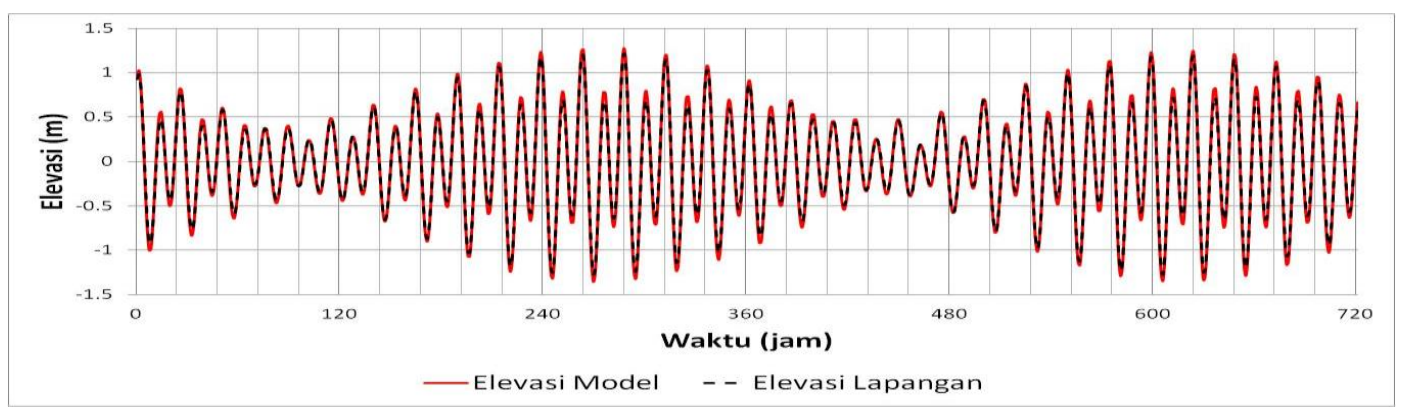

Gambar 6. Grafik validasi elevasi pasang surut

(masuk ke perairan teluk) dan bergerak ke arah barat (keluar dari perairan teluk).
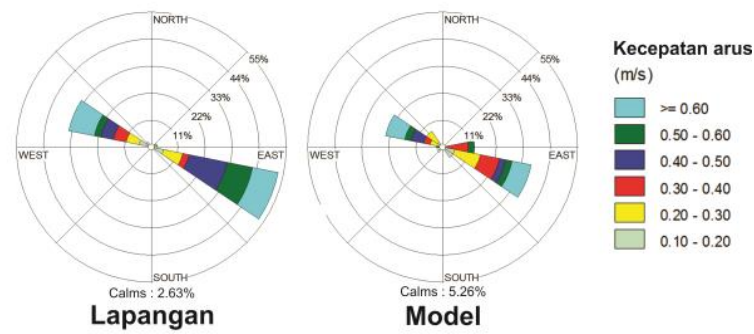

Gambar 7. Current rose pada mulut Teluk Benoa

Validasi arus juga dilakukan dengan membandingkan komponen kecepatan arus $\mathrm{U}$ (Gambar 8) dan V (Gambar 9) antara hasil simulasi model dan observasi lapangan. Validasi dari komponen $\mathrm{U}$ menujukkan pola yang serupa dengan korelasi yang tinggi yaitu 0,99 dan RMSE sebesar $0,06 \mathrm{~m} / \mathrm{s}$. Sedangkan pada komponen kecepatan arus $\mathrm{V}$ memiliki sedikit perbedaan dengan korelasi yang tinggi yaitu 0,9 dan RMSE sebesar $0,13 \mathrm{~m} / \mathrm{s}$. Menurut penelitian yang dilakukan Al Tanto (2017) perbedaan kecepatan arus pada komponen $\mathrm{V}$ di Teluk Benoa dapat diakibatkan karena adanya gangguan dari aktivitas lalu lintas kapal pada lokasi pengambilan data lapangan.

\subsubsection{Validasi TSS}

Validasi konsentrasi TSS dilakukan dengan membandingkan konsentrasi TSS hasil dari simulasi model numerik dengan observasi lapangan seperti terlihat pada Gambar 10.

Validasi model menunjukkan pola yang hampir sama dengan korelasi yang tinggi yaitu sebesar 0,79 . Konsentrasi TSS antara hasil dari simulasi model numerik dengan observasi lapangan menunjukkan nilai besaran yang berbeda dengan RMSE sebesar 0,01 kg/m3. Besarnya nilai RMSE dapat disebabkan karena adanya asumsi pada model bahwa mangrove yang berada di muara sungai dan sekitar Teluk Benoa tidak dipertimbangkan di dalam model. Mangrove merupakan trapper sedimen alami pada muara sungai yang dapat mengurangi konsentrasi TSS yang menuju perairan. Menurut penelitian yang dilakukan oleh Petra et al. (2012); Li et al. (2014); Siregar et al. (2016) menyatakan bahwa korelasi antara kerapatan mangrove terhadap transport sedimen adalah korelasi negatif yang kuat, sehingga semakin tinggi kerapatan mangrove konsentrasi TSS yang mencapai laut akan semakin berkurang.

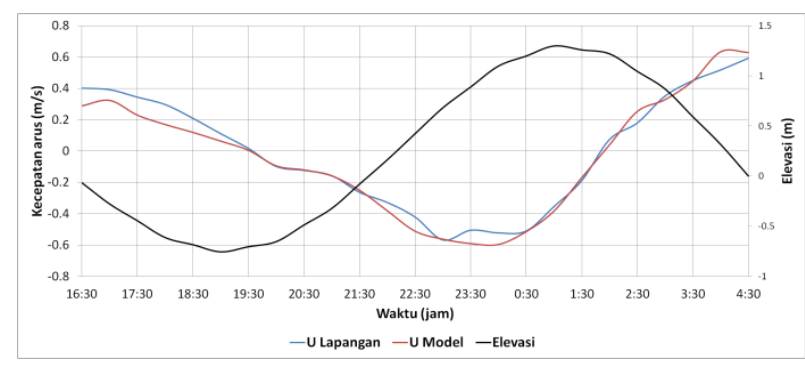

Gambar 8. Grafik validasi arus komponen timur-barat (U)

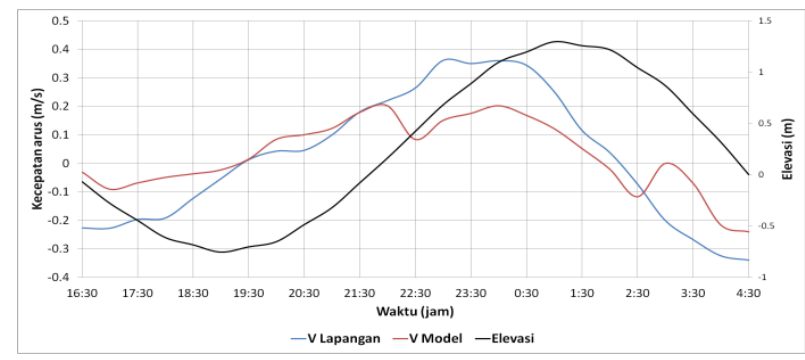

Gambar 9. Grafik validasi arus komponen utara-selatan (V)

\subsubsection{Validasi laju sedimentasi}

Validasi laju sedimentasi dilakukan dengan membandingkan antara laju sedimentasi hasil simulasi model dengan observasi lapangan seperti 


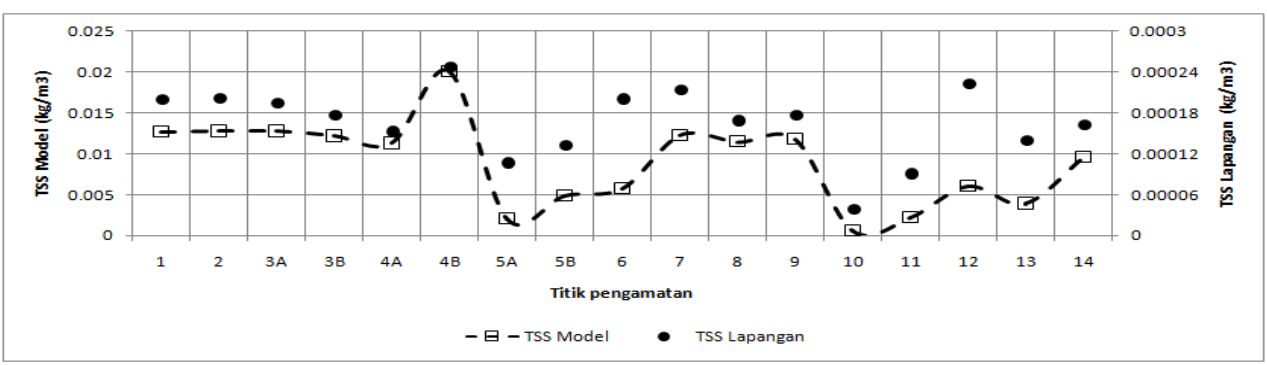

Gambar 10. Grafik validasi TSS

terlihat pada Gambar 11. Validasi model menunjukkan pola yang mirip dengan korelasi yang tinggi yaitu 0,98. Laju sedimentasi antara hasil dari simulasi model numerik dengan observasi lapangan menunjukkan nilai besaran yang berbeda dengan RMSE sebesar 1,56 $\mathrm{kg} / \mathrm{m}^{2} /$ hari. Besarnya nilai RMSE yang diperoleh disebabkan karena laju sedimentasi hasil observasi lapangan yang lebih besar dari hasil simulasi model. Perbedaan nilai laju sedimentasi dapat disebabkan karena adanya asumsi bahwa di Perairan Teluk Benoa tidak terdapat aktivitas kapal.

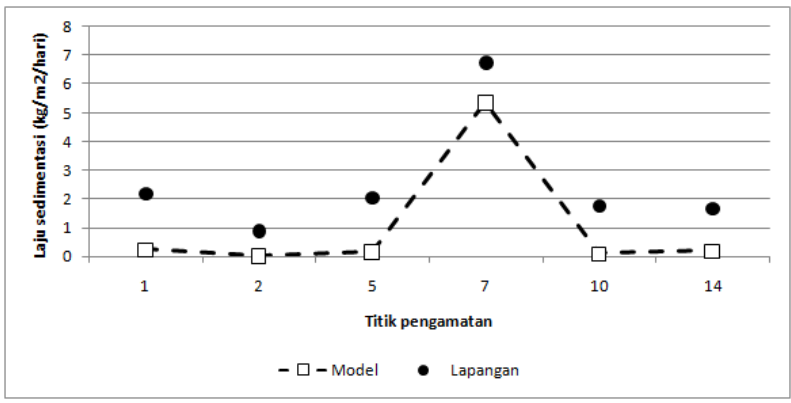

Gambar 11. Grafik validasi laju sedimentasi

Menurut Wang and Andutta (2013) asumsi ini berpengaruh terhadap tidak adanya aliran turbulence terhadap dasar perairan yang dapat disebabkan oleh pergerakan kapal di permukaan. Aliran turbulance inilah yang mengakibatkan ternyadinya erosi pada sedimen di dasar perairan yang akan mengendap kembali (Wang and Andutta, 2013), sehingga sedimentasi yang terjadi di lapangan juga dipengaruhi oleh erosi sedimen yang disebabkan oleh turbulence di dasar perairan. Kejadian ini dapat membuktikan lebih besarnya nilai laju sedimentasi di lapangan daripada hasil simulasi model.

\subsection{Laju sedimentasi di Teluk Benoa}

Pola sebaran laju sedimentasi ditunjukkan pada Gambar 12. Laju sedimentasi di Perairan Teluk
Benoa berkisar antara $1,08 \times 10^{-6}$ sampai 24,88 $\mathrm{kg} / \mathrm{m}^{2} /$ hari dengan rata-rata $0,57 \mathrm{~kg} / \mathrm{m}^{2} /$ hari. Tingginya laju sedimentasi di perairan diakibatkan karena rendahnya kecepatan arus, sehingga TSS cenderung akan mulai mengendap menuju dasar perairan (Franz et al., 2017). Laju sedimentasi di Teluk Benoa memiliki nilai yang tinggi pada daerah yang dekat dengan muara sungai serta daerah yang memiliki konsentrasi TSS yang tinggi pada lapisan dasar perairan seperti pada kanal yang berada pada bagian barat teluk dan perairan yang memiliki kanal yang merupakan jalur lalu lintas kapal. Menurut penelitian sebelumnya yang dilakukan oleh Qiao et al. (2009), Ge et al. (2015) dan Aprilia dan Pratomo (2017), pada daerah yang memiliki konsentrasi TSS yang tinggi di dekat dasar perairan, akan memiliki laju sedimentasi yang tinggi.

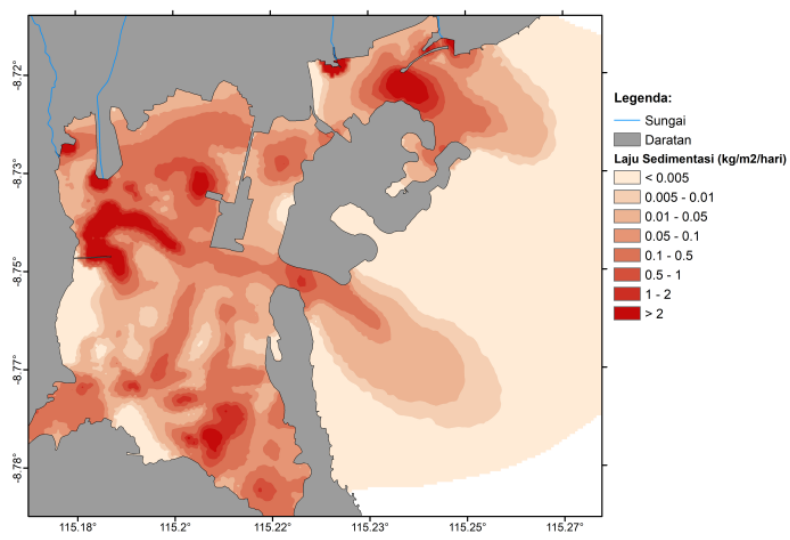

Gambar 12. Pola sebaran laju sedimentasi

Dibandingkan dengan daerah lain yang memiliki kondisi geografis, aktivitas antropogenik yang mirip serta masukan sedimen yang tinggi dari sungai seperti di Teluk Jakarta yang mencapai 3,9071 kg/m²/hari (Aprilia dan Pratomo, 2017) dan Pelabuhan Saint John di Canada yang mencapai 0,9667 kg/m²/hari (Leys and Mulligan, 2011), laju 
sedimentasi di Teluk Benoa masih dapat dikatakan relatif rendah. Pada daerah lain yang memiliki kondisi geografis yang mirip namun aktivitas antopogenik dan masukan sedimen yang lebih rendah dari sungai, memiliki laju sedimentasi yang lebih rendah dari sungai seperti di Sungai Wedung yang mencapai $0,031 \mathrm{~kg} / \mathrm{m}^{2} /$ hari (Roswaty et al., 2014) dan Perairan Pemangkat yang mencapai $0,11 \mathrm{~kg} / \mathrm{m}^{2} /$ hari (Solihudin et al., 2011). Berdasarkan perbandingan tingkat laju sedimentasi pada beberapa daerah terhadap kondisi lingkungan menunjukkan bahwa masukan sedimen dari sungai dan aktivitas antropogenik sangat mempengaruhi tingkat laju sedimentasi yang terjadi pada perairan tersebut.

\subsection{Perubahan kedalaman Perairan Teluk Benoa}

Perubahan kedalaman perairan di Teluk Benoa dapat dilihat pada Gambar 13. Pada daerah dekat dengan pelabuhan mengalami pendangkalan sekiar 0,03 sampai melebihi dari 0,1 m/tahun, selain itu beberapa daerah yang dekat dengan sungai juga mengalami pendangkalan yang tinggi yaitu melebihi dari $0,1 \mathrm{~m} /$ tahun dengan pendangkalan maksimum yaitu $0,53 \mathrm{~m} /$ tahun dan rata-rata pendangkalan adalah $0,0048 \mathrm{~m} /$ tahun

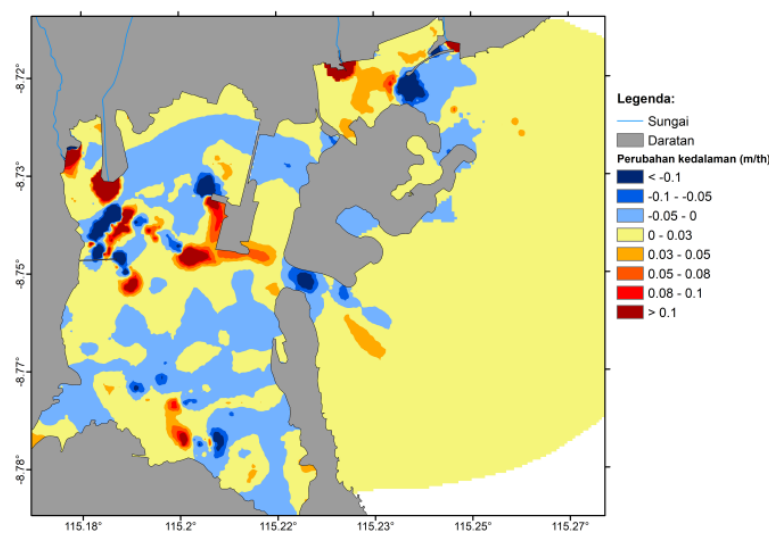

Gambar 13. Pola perubahan kedalaman

Selain pendangkalan, beberapa daerah junga mengalami pendalaman yaitu daerah pada bagian dekat dengan Sungai Buaji dan Loloan serta pada mulut teluk. Menurut penelitian Leys and Mulligan (2011), perubahan kedalaman pada perairan diakibatkan karena proses deposisi dan erosi yang terjadi di perairan tersebut. Dilihat dari selisih antara deposisi dan erosi seperti Gambar 14, pola pendangkalan di Teluk Benoa memiliki kemiripan sehingga dapat menujukkan pengaruh dari deposisi dan erosi terhadap perubahan kedalaman di Teluk Benoa.

Pelabuhan Benoa merupakan daerah yang paling riskan mengalami pendangkalan, terutama pada tempat turning kapal dan pelabuhan bagian selatan yang merupakan tempat yang sangat penting bagi aktivitas Pelabuhan Benoa. Hasil ini diperkuat dengan adanya bukti bahwa pada daerah tersebut sering dilakukannya pengerukan oleh pihak Pelabuhan Benoa sejak tahun 2011 (Tribunnews, 2015) untuk mengantisipasi pendangkalan yang terjadi. Dibandingkan dengan daerah lain, pendangkalan yang terjadi di Teluk Benoa masih dapat dikatakan rendah. Pendangkalan di Teluk Jakarta mencapai 0,84 $\mathrm{m} /$ tahun (Aprilia dan Pratomo, 2017) dan di Pelabuhan Saint John di Canada yang mencapai 0,7 m/tahun (Leys and Mulligan, 2011). Bila dibandingkan dengan dua penelitian sebelumnya, pendangkalan di Teluk Benoa masih terbilang rendah.

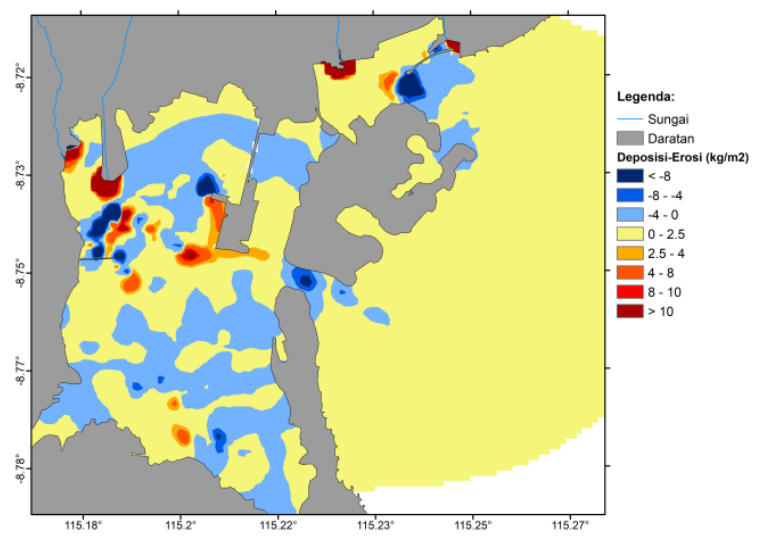

Gambar 14. Pola seliesih antara deposisi dengan erosi

\section{Simpulan}

Laju sedimentasi di Teluk Benoa memiliki nilai minimum $1.08 \times 10^{-6}$ dan maksimum 24.88 $\mathrm{kg} / \mathrm{m}^{2} /$ hari dengan rata-rata $0,57 \mathrm{~kg} / \mathrm{m}^{2} /$ hari. Dimana laju sedimentasi yang tinggi terjadi dibagian barat teluk pada kanal aliran sungai dan dibagian utara teluk di antara Pulau Serangan dan Pantai Mertasari.

Daerah yang berpotensi mengalami pendangkalan di Teluk Benoa meliputi daerah Selatan Pelabuhan Benoa yang mencapai 0,23 $\mathrm{m} /$ tahun, perairan di Utara Pulau Serangan yang mencapai $0,008 \mathrm{~m} /$ tahun, dan daerah yang dekat dengan muara sungai yang mencapai $0,35 \mathrm{~m} /$ tahun. 


\section{Ucapan terimakasih}

Dalam pelaksanaan penelitian ini penulis banyak mendapatkan bantuan baik dari perorangan ataupun instansi/lembaga. Oleh karena itu, pada kesempatan ini penulis ingin menyampaikan ucapan terimakasih yang sebesar-besarnya kepada kepala dan staf Laboratorium Komputasi, serta teman-teman mahasiswa Fakultas Kelautan dan Perikanan Universitas Udayana atas bantuannya selama penelitian.

\section{Daftar Pustaka}

Al Tanto, T., Wisha, U. J., Kusumah, G., Pranowo, W. S., Husrin, S., Ilham, I., \& Putra, A. (2017). Karakteristik Arus Laut Perairan Teluk Benoa-Bali. Jurnal Ilmiah Geomatika, 23(1), 37-48.

Aprilia, E., \& Pratomo, D. G. (2017). Pemodelan Hidrodinamika 3-Dimensi Pola Persebaran Sedimentasi Pra dan Pasca Reklamasi Teluk Jakarta. Jurnal Teknik ITS, 6(2), A539-544.

Ardana, K., \& Mahendra, M. S. (2012). Study of pollutant distribution in Benoa Bay using numerical simulation and satellite data. Ecotrophic: Journal of Environmental Science, 3(2), 81-86

Chen, S. N., Geyer, W. R., Sherwood, C. R., \& Ralston, D. K. (2010). Sediment transport and deposition on a river dominated tidal flat: An idealized model study. Journal of Geophysical Research: Oceans, 115(C10).

Chizom Dike, C., \& Agunwamba, J. C. (2013). Modelling Of Sediments Concentration Distribution In Dredged Canals Of The Niger Delta Estuarine Region, Nigeria. Journal of Urban and Environmental Engineering, 7(2), 330-339.

Eaton, A. D., Clesceri, L. S., Greenberg, A. E., \& Franson, M. A. H. (1995). Standard methods for the examination of water and wastewater, (19th Edition). Washington, DC., USA: American Public Health Association.

Franz, G., Delpey, M. T., Brito, D., Pinto, L., Leitão, P., \& Neves, R. (2017). Modelling of sediment transport and morphological evolution under the combined action of waves and currents. Ocean Science, 13(5), 673.

Ge, J., Shen, F., Guo, W., Chen, C., \& Ding, P. (2015). Estimation of critical shear stress for erosion in the Changjiang Estuary: A synergy research of observation, GOCI sensing and modeling. Journal of Geophysical Research: Oceans, 120(12), 8439-8465.

Guerreiro, M., Bustorff Fortunato, A., Freire, P., Rilo, A., Taborda, R., Freitas, M. C., ... \& Azevedo, A. (2015). Evolution of the hydrodynamics of the Tagus estuary (Portugal) in the 21st century. Revista de Gestão Costeira Integrada-Journal of Integrated Coastal Zone Management, 15(1), 65-80
Hendrawan, I. G., \& Asai, K. (2008). Study of Suspended Sediment Distribution Using Numerical Model and Satellite Data in Benoa Bay-Bali, Indonesia. International Journal of Remote Sensing and Earth Sciences, 5, 84-91.

Hendrawan, I. G., \& Ardana, I. K. (2010). Numerical calculation of phosphate transport in Benoa Bay, Bali. International Journal of Remote Sensing and Earth Sciences, 6, 39-45.

Hendrawan, I. G., \& Asai, K. (2014). Numerical study on tidal currents and seawater exchange in the Benoa Bay, Bali, Indonesia. Acta Oceanologica Sinica, 33(3), 90-100.

Hendrawan, I. G., Uniluha, D., \& Maharta, I.P.R.F. (2016). Karakteristik Total Padatan Tersuspensi (Total Suspended Solid) Dan Kekeruhan (Turbidity) Secara Vertikal Di Perairan Teluk Benoa, Bali. Journal of Marine and Aquatic Sciences, 2(1), 29-33.

Kim, H. J., Suh, S. W., Seok, J. S., \& Park, W. K. (2017). Sedimentation for a Flood-dominant Estuarine Harbor Induced by Anthropogenic Activities. Journal of Coastal Research, 79(sp1), 339-343.

Leys, V., \& Mulligan, R. P. (2011). Modelling coastal sediment transport for harbour planning: selected case studies. In Sediment Transport. InTech, 2011(2), 332-346.

Li, L., Wang, X. H., Andutta, F., \& Williams, D. (2014). Effects of mangroves and tidal flats on suspendedsediment dynamics: Observational and numerical study of Darwin Harbour, Australia. Journal of Geophysical Research: Oceans, 119(9), 5854-5873.

Matsumoto, K., Ooe, M., Sato, T., \& Segawa, J. (1995). Ocean tide model obtained from TOPEX/POSEIDON altimetry data. Journal of Geophysical Research: Oceans, 100(C12), 25319-25330.

Ningsih, N. S., \& Al Azhar, M. (2013). Modelling of hydrodynamic circulation in Benoa Bay, Bali. Journal of marine science and technology, 18(2), 203-212.

Noya, Y. A., Purba, M., Koropitan, A. F., \& Prartono, T. (2017). Cohesive Sediment Transport Modeling On Inner Ambon Bay. Jurnal Ilmu dan Teknologi Kelautan Tropis, 8(2), 671-687.

Petra, J. L., Sastrawibawa, S., \& Riyantini, I. (2012).Pengaruh Kerapatan Mangrove Terhadap Laju Sedimen Transpor di Pantai Karangsong Kabupaten Indramayu. Jurnal Perikanan Kelautan, 3(3), 329-337.

Qiao, S., Shi, X., Zhu, A., Liu, Y., Bi, N., Fang, X., \& Yang, G. (2010). Distribution and transport of suspended sediments off the Yellow River (Huanghe) mouth and the nearby Bohai Sea. Estuarine, Coastal and Shelf Science, 86(3), 337-344.

Rachman, H. A., Hendrawan, I. G., \& Putra, I. D. N. N. (2016). Studi Transpor Sedimen Di Teluk Benoa Menggunakan Pemodelan Numerik. Jurnal Kelautan: 
Indonesian Journal of Marine Science and Technology, 9(2), 144-154.

Risuana, I. G. S., Hendrawan, I. G., \& Suteja, Y. (2017). Distribusi Spasial Total Padatan Tersuspensi Puncak Musim Hujan Di Permukaan Perairan Teluk Benoa, Bali. Journal of Marine and Aquatic Sciences, 3(2), 223232.

Roswaty, S., Muskananfola, M. R., \& Purnomo, P. W. (2014). Tingkat Sedimentasi di Muara Sungai Wedung Kecamatan Wedung, Demak. Management of Aquatic Resources Journal, 3(2), 129-137.

Shaw, E. M., Beven, K. J., Chappell, N. A., \& Lamb, R. (2010). Hydrology in practice. (4th ed.). Boca Raton, Florida, USA: CRC Press.

Siregar, R. H., Djayus, Y., \& Mutadi, A. (2016). Hubungan Kerapatan Mangrove terhadap Laju Sedimen Transpor di Wilayah Pesisir Desa Pulau Sembilan Kabupaten Langkat Sumatera Utara. Aquacoastmarine, 14(4), 29-38.

SNI. (2004). Air dan air limbah-Bagian 3: Cara uji padatan tersuspensi total (Total Suspended Solid, TSS) secara gravimetri. 06-6989.3.

Solihuddin, T. B., Sari, E. M., Kusumah, G. (2011). Prediksi Laju Sedimentasi Di Perairan Pemangkat, Sambas Kalimantan Barat Menggunakan Metode Pemodelan. Buletin Geologi Tata Lingkungan (Bulletin of Environmental Geology), 21(3), 117 - 126
Solihuddin, T., \& Kusumah, G. (2014). Sedimentary Environments of the Inshore Pemangkat Region Sambas, West Kalimantan (Lingkungan Sedimen di Perairan Pemangkat, Sambas, Kalimantan Barat). ILMU KELAUTAN: Indonesian Journal of Marine Sciences, 19(1), 19-26.

Tribunnews. (2016). Nelayan Keluhkan Parahnya Sedimentasi Di Teluk Benoa. [online] Tersedia di: http://www.tribunnews.com/regional/2016/01/30/nela yan-keluhkan-parahnya-sedimentasi-di-teluk-benoa, [diakses: 9 Oktober 2016].

Van Kessel, T., Winterwerp, H., Van Prooijen, B., Van Ledden, M., \& Borst, W. (2011). Modelling the seasonal dynamics of SPM with a simple algorithm for the buffering of fines in a sandy seabed. Continental Shelf Research, 31(10), S124-S134.

Wang, X. H., \& Andutta, F. P. (2013). Sediment transport dynamics in ports, estuaries and other coastal environments. In Sediment Transport Dynamics in Ports, Estuaries and Other Coastal Environments. InTech, 13(2), 953-978.

Weilbeer, H. (2014). Sediment transport and sediment management in the Elbe estuary. Die Küste, 81 Modelling, (81), 409-426.

Zhang, P., Wai, O. W., Chen, X., Lu, J., \& Tian, L. (2014). Improving sediment transport prediction by assimilating satellite images in a Tidal Bay model of Hong Kong. Water, 6(3), 642-660.

(C) 2018 by the authors; licensee Udayana University, Indonesia. This article is an open access article distributed under the terms and conditions of the Creative Commons Attribution license (http://creativecommons.org/licenses/by/3.0/). 